\title{
Heading for Tomorrow: Resilience Strategies for Post-COVID-19 Grocery Supply Chains
}

\author{
Lorenzo Bruno Prataviera ${ }^{1,2} \mathbb{C}^{(}$, Alessandro Creazza $^{3, *} \mathbb{D}$, Marco Melacini ${ }^{1}$ and Fabrizio Dallari $^{3}$ \\ 1 Department of Management, Economics and Industrial Engineering, Politecnico di Milano, 20156 Milan, Italy; \\ lorenzobruno.prataviera@polimi.it or lorenzo.prataviera@cranfield.ac.uk (L.B.P.); \\ marco.melacini@polimi.it (M.M.) \\ 2 Centre for Logistics and Supply Chain Management, Cranfield School of Management, Cranfield University, \\ Bedfordshire MK43 0AL, UK \\ 3 School of Industrial Engineering, LIUC University, 21053 Castellanza, Italy; fdallari@liuc.it \\ * Correspondence: acreazza@liuc.it; Tel.: +39-033-157-2527
}

Citation: Prataviera, L.B.; Creazza, A.; Melacini, M.; Dallari, F. Heading for Tomorrow: Resilience Strategies for Post-COVID-19 Grocery Supply Chains. Sustainability 2022, 14, 1942. https://doi.org/10.3390/su14041942

Academic Editors

Jurgita Antuchevičienè and

Andrea Appolloni

Received: 28 December 2021

Accepted: 3 February 2022

Published: 9 February 2022

Publisher's Note: MDPI stays neutral with regard to jurisdictional claims in published maps and institutional affiliations.

Copyright: (c) 2022 by the authors Licensee MDPI, Basel, Switzerland. This article is an open access article distributed under the terms and conditions of the Creative Commons Attribution (CC BY) license (https:// creativecommons.org/licenses/by/ $4.0 /)$

\begin{abstract}
Supply chain resilience is a critical capability needed to compete in the current turbulent and unpredictable business environment, but many companies still tend to underestimate its relevance. In the wake of the COVID-19 pandemic, understanding which supply chain impacts influence the policies and actions undertaken when resilience is concerned is important. This study investigated the relationships between the impacts experienced at the different supply chain tiers during the pandemic, and explored which impacts could drive perceptions towards developing resilience strategies in the future. A survey instrument was developed adopting a mid-range approach, targeting manufacturers active in the Italian grocery supply chain. Data were analysed using partial least square structural equation modelling (PLS-SEM). Results showed that source-related impacts deeply affect make- and delivery-related impacts, and make-related impacts mainly influence the perceptions about future resilience strategies. In fact, manufacturers appear to be primarily interested in those strategies ensuring the continuity of their intrinsic operations. The study could inform theory and practice about companies' decisions towards the adoption of certain approaches. Also, it highlights promising research avenues related to deepening understanding of how perceptions could predict future intentions to engage in protective actions to adequately cope with potential future disruptions.
\end{abstract}

Keywords: COVID-19; supply chain resilience; survey; grocery industry; risk management; PLS-SEM

\section{Introduction}

Modern supply chains (SCs) are today more vulnerable than ever [1,2], as natural disasters, industrial disputes, and terrorism have increasingly resulted in serious disruptions to SC activities [3,4]. Consistently with the 'era of turbulence' proclaimed by [5], in 2020 the COVID-19 pandemic swept across the globe in a matter of months, jeopardizing lives, upending businesses, and setting off a worldwide economic slump [6,7]. It introduced huge uncertainties in both supply and demand, highlighting the importance for companies to properly handle SC risks [8,9]. However, it also provided rich opportunities for researchers to conduct the empirical and event-based research about supply chain risk management (SCRM) that has been called for several times in the last two decades [6,10]. Consequently, SCRM has gained traction once again, both for practitioners and academics [11].

Being in the 'era of turbulence', managing SC risks to reduce vulnerability and ensure business continuity is often problematic [12,13]. SC resilience has been proposed as a critical capability, necessary to regain a new stable position, recovering or returning close to its original state, after perturbations $[14,15]$. However, the literature suggests that many companies are not well prepared for the challenges they have to confront nowadays [16,17]. Despite the fact that a number of prominent examples led companies to reconsider a structured SCRM approach as an important field of action, the idea that nobody gets credit 
for fixing problems that never happened clearly emerged in the past decade and it is still firmly present in today's business strategies [2,18]. Many companies underestimate the relevance of resilience, not developing proper plans and hoping for things to just go back to normal at short notice [6]. Nevertheless, overlooking resilience strategies can lead organisations to suffer negative impacts due to disruptions. Some scholars have investigated how resilience strategies positively affect performance outcomes and help mitigate risks and related impacts [11]. However, there is lack of research about how risk impacts can lead to shaping resilience strategies in organisations' plans for the future.

Studying how future resilience strategies are influenced by factors such as the (negative) impacts of disruptions can enhance the understanding of what kind of priority factors drive the actions and initiatives of organisations towards better SC resilience, and how risks and impacts are perceived by organisations themselves [19]. Perception plays a critical role in shaping the policies and actions undertaken when risk management is concerned [20]. It can inform theory and practice about companies' decisions towards the adoption of certain approaches in order to confront experienced disruptions and to plan actions aimed at coping with potential future disruptions. Better understanding of these factors can then improve the overall level of SC resilience in its four phases (prepare, respond, recover, and maintain) and enable better communication of supply chain risks and resilience strategies [12,15].

Based on these premises, our study investigated the perceptions underlying the adoption of SC resilience strategies. The following research question $(\mathrm{RQ})$ was formulated:

RQ: How much do SC impacts following disruptions raise interest towards future SC resilience strategies?

A survey instrument was developed to collect responses from SC managers on the different SC impacts they experienced in their SC processes in addition to the level of importance assigned to future SC resilience initiatives as a foundation for the development of SCRM strategies for coping with future disruptions. To limit the research scope and simultaneously address the urgency to provide pragmatic answers to contingent issues [6] the investigation was limited to a specific empirical domain, thus resulting in a mid-range theory approach [21]. Manufacturers active in the Italian grocery SC were considered. In fact, besides also often being the object of studies on supply chain risk management in the form of food supply chains, grocery SCs have been severely affected during the COVID-19 pandemic [22]. Moreover, Italy was one of the first European countries to be hit by the pandemic $[23,24]$ and experience major SC issues because of it (e.g., plant shutdowns or truck driver shortages) [25]. Ultimately, manufacturers were considered as they have been struggling with wide SC challenges, with significant impacts due to inventory levels soaring or dropping, as well as replenishment and fulfilment issues in the wake of governments' lockdowns.

The paper is organised as follows: Related literature is first proposed, offering the theoretical background behind the study. The research methodology is then described, followed by the presentation of the results and the related discussion. Lastly, conclusions are drawn along with avenues for future research.

\section{Literature Review}

SCs are inherently characterised by uncertainty and vulnerability, being exposed to a wide array of possible risks [26,27]. The concept of SCRM emerged from the efforts to reduce vulnerability to risks $[1,28]$, and relates to the implementation of strategies to manage both every day and exceptional risks along the SC to ensure business continuity [13]. Generally speaking, SCRM consists of four key management aspects: (1) assessing the risk sources for SCs; (2) defining the SC adverse impacts; (3) identifying the risk drivers; (4) mitigating SC risks by developing opportune strategies $[29,30]$. 


\subsection{SC Risk Sources, Impacts, and Drivers}

Different definitions of risk in a SC context are provided in the literature [11,31]. SC risk is usually defined as the variation in the distribution of possible SC outcomes, their likelihood, and their subjective values [29]. Risk could thus be operationalised by using the relationship between the range of possible negative outcomes (severity or impact) and the distribution of the corresponding likelihood of occurrence for each outcome [18,30]. SC risks can then be categorised in many different ways and from different perspectives [28,32]. Many scholars have proposed classifications in the form of typologies and/or taxonomies of risks [29,33]. In this study, SC risks have been distinguished into disruption and operational ones [34].

A SC disruption is an unintended situation that significantly threatens normal business operations of the firms in the supply chain [35]. This refers to natural hazards, socio-political instability, civil unrest, economic disruptions, and terrorist attacks but also pandemics $[4,25,34]$. While disruption risks are difficult to manage, operational risks are relatively more controllable [11]. Operational risks usually concern supply-demand coordination, and examples can relate to quality or delivery problems [36]. A wide array of possible operational risk classifications, including the related impact, has been proposed in previous literature [28,30,37]. For instance, risks can be distinguished as supply-side (related to purchasing and supplier relationships) or demand-side (related to downstream SC operations) [29,35]. Moreover, how manufacturing operations are organised by single firms can cause deviations from the expected outcome in terms of quality, quantity, and time, e.g., workers unavailability due to labour shortages or strikes can reduce the operational rate [36].

To better connect with the current practice, risk types and related impacts can be related to the management processes intrinsic in functional SCs that are advocated by the Supply Chain Operations Reference (SCOR) Model [33]. The SCOR model provides a set of practical guidelines for analysing SC management practices [38]. Leveraging the SCOR model, three main types of risk (having distinct impacts) can be identified, i.e., supply, manufacturing process, and delivery risk $[39,40]$.

Supply risks reside in purchasing, supplier activities, and supplier relationship management, and can be critical for the operational processes of manufacturing firms [17,31]. The source-related impacts may be operationalised in terms of capacity constraints or shortages as well as poor logistics performance, leading to late deliveries or raw material shortages $[9,35]$. Manufacturing process risks relate to efficiently transforming raw materials into finished goods to meet SC demand in a timely manner [41]. Make-related negative impacts on SCs could thus be driven by plant closure or reduced operational capacity because of manpower shortages [6,9]. In turn, manufacturing risks can have huge consequences on the downstream SC operations [29]. Delivery risks basically refer to outbound logistics, which has been highlighted as a critical link in SC management [14,39]. Delivery-related impacts mainly concern the physical distribution of products to endcustomers with particular issues concerning transport operations (e.g., a truck driver strike) and distribution networks (e.g., warehouse shutdowns) [22,35]. In addition, severe impacts could be driven by finished product shortages, which are affected in turn by negative impacts arising upstream in the SC $[9,36]$.

\subsection{SC Resilience Strategies}

The concept of SC risk is closely interconnected with the notion of SC vulnerability, which is an exposure to serious disturbance whose deviations cause negative effects or consequences [18,28].

A proven capability to face SC vulnerability is resilience [13]. Resilience implies that a system can adapt in order to regain a new stable position (recover, or return close to, its original state) after perturbations $[12,14]$. Consequently, resilience is usually defined in terms of speed to get back to normal and often includes the definition of mitigation capabilities [2,42]. However, resilience must be understood not only as the reactive ability 
to recover from upheavals, but also as a proactive and structured subset of capabilities within the SC to cope with unforeseen events $[15,43]$. SC resilience can thus be defined as 'the adaptive capability of the supply chain to prepare for unexpected events, respond to disruptions, and recover from them by maintaining continuity of operations at the desired level of connectedness and control over structure and function' [12]. Resilience initiatives can be clustered according to whether they are introduced before, during, or after a disruption, thus highlighting their proactiveness or reactiveness $[13,44]$. This relates also to what the main phases of SC resilience could be, namely readiness, response, recovery, and maintaining [15].

Proactive strategies imply that the SC implements measures to cope with turbulence in advance $[45,46]$. The proactive approach requires decision-makers to be able to forecast possible future changes and resist these forecasted changes, and it is often related to SC robustness [11,47]. Incorporating redundancy is a commonly used measure to increase SC robustness [45]. Increasing safety stock, maintaining multiple suppliers, activating back-up options, and adding capacity are the most common forms of redundancy [34,37]. Indeed, redundancy often encompasses increasing product availability by 'keeping some resources in reserve to be used in case of a disruption' [48]. Also, multiple sourcing could be adopted for both raw materials and logistics services [22]. The reduced reliance on single plants or suppliers could then be accompanied by rebalancing supply lines to include more local and nearshore suppliers [6].

Along with proactiveness, reactiveness is also needed including actions introduced after a risk event has occurred [19]. They correspond primarily to rapidly responding to restore the initial stable configuration [13]. Therefore, they are normally related to SC agility $[34,49]$. However, reactiveness includes a portion of the preparatory components of proactiveness [15]. For instance, bulking up inventory across the chain mitigates the risk of stock-out, allowing for fulfilling orders from alternative sites if there is a logistics bottleneck [6]. Also, a relevant problem could be the need to focus on critical supplies, and essential products and customers. Companies can position inventories closer to customers to reduce lead times, or redeploy resources to meet essential demands [22]. Order allocation to customers can be critical in the case of scarce supplies and capacity, leading to sub-optimal policies either favouring the most profitable customers, or uniformly sharing available products among all the customers.

During the COVID-19 pandemic, the resilience strategies adopted by organisations to recover from the current pandemic (and prepare for future 'unknown' disruptions) revolved around an array of main actions $[9,10]$ : increasing production and distribution capacity of supply chains and related utilisation levels; improving the workforce management at plants and distribution centres; restructuring logistics and supply chain networks (e.g., facility location and inventory allocation); introducing new partnerships with logistics service providers and suppliers of raw materials; revisiting order allocation strategies; streamlining product portfolio to focus on a reduced product range, less sensitive to disruptions and more manageable in constrained fulfilment capacity conditions $[6,43]$.

\section{Materials and Methods}

The COVID-19 pandemic demonstrated that unprecedented disruptions could lie behind any time corner and confirmed that turbulence characterises modern SCs $[5,7,25]$. Moreover, it offered a unique opportunity to address the call for empirical research to improve current knowledge about SCRM [11]. As many companies exhibited a lack of preparedness and the need for greater SC resilience [6], a better understanding of how companies might cope with SC resilience can be beneficial. In fact, how disruptions' impact on SC activities could affect the perceptions of SC managers towards risk management and related resilience strategies has not been widely discussed in the literature so far [22]. This study specifically aimed at investigating the relationships between the concrete impacts experienced at the different SC tiers during the pandemic, and what impacts could drive perceptions towards developing resilience strategies in the future. 


\subsection{Survey Design: Population, Sample, and Data Collection}

A single-source survey study considering single respondents was conducted [50,51], focusing on the association between individual companies' negative SC impacts and future perceptions. To limit the scope and sharpen the study's contribution we chose a midrange approach [21]. Among the various possible industries to be studied in relation to the impact of COVID-19 on SCs, we decided to focus on the grocery industry as it is crucial for the daily provision of essential products [52]. Additionally, grocery SCs face specific vulnerabilities due to the limited shelf life of food, variability in quality and availability of raw materials, such as organic products, along with important cyber and information risk implications $[20,46]$. Even more importantly, grocery SCs have been among the most severely affected SCs during the COVID-19 pandemic, and consequently offer unique opportunities to study ways in which SC resilience can be enhanced in the face of disruption [22]. Moreover, grocery SCs have been the object of several pieces of production research and SC studies, proving their relevance to this field of research. In this broad landscape we selected the Italian grocery industry. Italy was the first country to be hit by the pandemic in Europe, and grocery firms experienced wide SC disruption impacts primarily driven by end customers' panic buying [23-25]. On top of this, the Italian grocery industry also represents an appropriate context to be investigated given its international relevance: it is included among the top five markets in Europe for logistics flows and turnover generated, and is the fastest growing market in terms of volume and nominal value across Europe [53]. Within the grocery SC, which is composed of three main actors (manufacturers, logistics service providers, and retailers [20]), we decided to focus our exploratory study on the manufacturers, as they were the first players in the SC having to rapidly deal with backup sources of supply and develop strategies to manage contingent shortages, thus representing an appropriate category of organisations to address within the scope of this study. We built the sample for our survey according to typical principles suggested by the literature to conduct an exploratory study [54]. First, we wanted to access as many organisations as possible within a reasonable timescale. Consistent with the focus of our research, the sample was determined in collaboration with GS1 Italy, which is the main trade association of peers in the grocery industry in Italy, which provided a list of their company members, numbering over 200 large grocery manufacturing companies. Companies were first contacted by e-mail to identify the most suitable informant in relation to SC management and resilience. Given the focus of our study, managers in charge of SC management or logistics were chosen as potential respondents for this survey since they were expected to be the most appropriate professionals to provide an SC risk management perspective. Consistent with [20], a minimum working experience of five years in the industry at middle to senior management levels was included as a further respondent selection criterion. Having already experienced the SC mechanisms and challenges of the sector, these respondents could provide a better level of understanding and more pertinent perception of the risks. From the companies contacted a total of 66 answers were received $(66 / 228)$, representing a response rate of $29 \%$, which is in line with other studies dealing with small-sized samples with around 70 respondents [55]. To verify that our sample size does not compromise the validity of this study we relied on the methodological guidance provided by [56,57], which, based on Cohen's [58] rule, provide indications related to the structure of the theoretical model to be adopted, the statistical features of the study, and the sample size. According to this literature, with a sample size equal to 66 it is possible to obtain statistical power equal to $80 \%$, a significance level equal to $1 \%$, and a minimum $R^{2}$ equal to 0.25 , provided that the maximum number of arrows pointing at a construct is not greater than 6 .

\subsection{Data Collection: Survey Instrument Development}

A well-designed survey questionnaire is vital for collecting valid and usable data [51]. To establish the content validity of the survey instrument, SC impacts and resilience strategies (i.e., constructs included in the investigation framework) were defined upon 
triangulating the academic and practitioners' literature on risk management and SC management, and those features relevant for the investigated industry were isolated. The construct named 'Source-related impacts' was introduced to ascertain the impacts experienced by manufacturers in relation to those typical elements causing disruptions in the proper working of the sourcing process. The measure consisted of two items (i.e., late deliveries and raw material shortages) [6,9]. The construct 'Make-related impacts' was introduced to evaluate the typical impacts suffered by manufacturers in the production tier as far as the unavailability of strategic resources was experienced. Also in this case the measure consisted of two items (i.e., reduced operational capacity at plants, and manpower shortages) [36]. The 'Delivery-related impacts' ascertained impacts related to those elements negatively affecting the delivery processes in the downstream side of the SC. Three items were considered (reduced operational capacity at warehouses, driver shortages, and finished product shortages) [9,22]. Finally, the construct 'Future resilience strategies' was introduced to assess the level of interest perceived by SC managers in relation to those typical strategies applicable to improve the resilience in the FMCG SC as seen by manufacturing companies. Leveraging the literature, it was operationalised through five items (i.e., multiple sourcing for raw materials, multiple sourcing for logistics services, additional operational capacity in terms of additional manpower, flexible order allocation policies in terms of product range prioritisation, and network re-design in terms of inventory positioning closer to customers) [9]. The identified constructs are summarised and illustrated in the conceptual framework displayed in Figure 1, while the items used to measure the constructs are detailed in Appendix A.

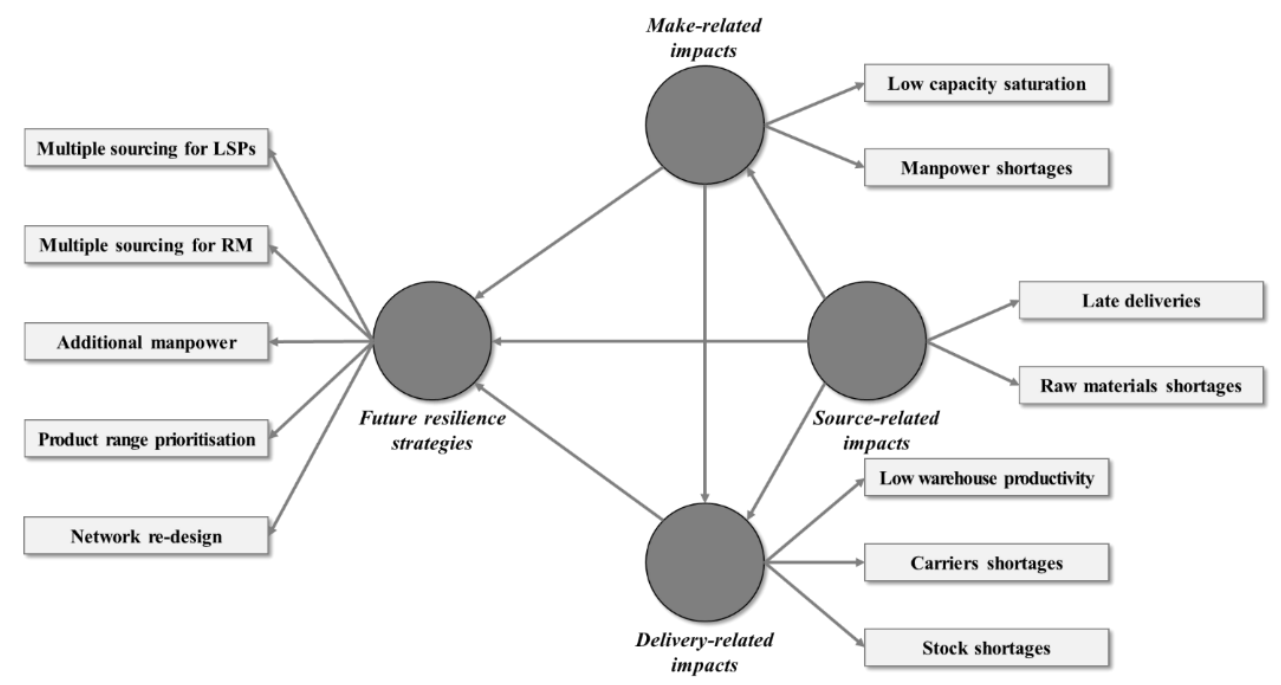

Figure 1. Research conceptual framework.

Operational definitions for such impacts and strategies were derived from the aforementioned sources, and questions were formulated according to both academic and secondary sources. In particular, this study aimed at exploring what causal relationships might exist among impacts at different SC tiers. Also, it investigated how the different impacts could affect perceptions and increase the interest towards improving resilience strategies in the future.

Respondents were asked to indicate how their firms were negatively affected (SC impacts) by the COVID-19 disruption, and their interest towards resilience strategies in the future. Participants responded to the questions on a five-point Likert scale, where 1 indicated low impact or interest, and 5 indicated high impact or interest; responses are thus their subjective evaluations of the organisation they represent [59]. A preliminary questionnaire was thus drafted, including firm background information. To further refine the survey instrument, it was pre-tested through pilot interviews [35,51]. Pilot testing allowed for improving survey design and question wording, as well as highlighting possible question 
biases [50]. First, a pre-test phase was set up providing the questionnaire to four colleagues affiliated to the authors' institutions. This helped in understanding whether the questionnaire accomplished the study objectives. Second, the survey was administered through the SurveyMonkey web survey application $[60,61]$ to a small pre-test sample, composed of four companies, with whom the authors had previously collaborated. This second phase helped evaluate possible improvement areas in the questionnaire through the assessment of the content of the answers provided compared to what was expected [51]. Furthermore, virtual meetings were arranged to collect feedback about whether the questions were clear, as well as whether there were any problems in answering them [61]. The final version of the questionnaire was administered through the same web application.

\subsection{Data Analysis}

In this study, structural equation modelling (SEM) using the partial least square (PLS) method was adopted [56]. PLS is one of the most widely used methods in exploratory research for investigating the direct and indirect effects of numerous variables simultaneously [62], also in supply chain management and risk and resilience literature [63]. The PLS-SEM approach is a non-parametric method not requiring multivariate normality of data, and is most often used when data is non-normal or the sample size is small [57]. Its application is aimed at maximising the explained variance of the endogenous latent constructs and minimising the unexplained variances [40,64]. As the research field of the present study is less mature and exploratory in nature than other SCRM topics, PLS-SEM was deemed an appropriate technique, as it allowed for dealing with non-normality of data distribution given the small sample size, compared to other factor-based methods that are less focused on prediction in exploratory settings such as this study $[57,65]$ where there is little guidance on how to specify the measurement models. Finally, we adopted the point of view of reflective indicators, since this is the dominant perspective in the discipline of SC management research [55].

\section{Results}

\subsection{Model Validation-Validity and Reliability of the Measurement Model}

In the present research common method bias might exist, as all the scales use five-point Likert scales and responses are from a single respondent [66]. A collinearity test for the assessment of vertical and lateral collinearity was thus carried out [67]. We calculated the Variance Inflation Factors (VIFs) for the constructs of the model (Table 1). The values of VIFs for each construct are below the critical threshold of 3.3, and this means that common method bias is not present in our study [68]. We then checked the measurement indicators' reliability, measuring the value of the loadings and their squared value, which according to the literature should be equal to or greater than 0.7 and not smaller than 0.4 [57]. Table 2 reports the values of the indicators: in two cases the value of the loadings is close to 0.7 and the squared value is below 0.7 but all above 0.4 , showing a good level of reliability.

Table 1. Collinearity test for the latent variables (VIF values).

\begin{tabular}{ccccc}
\hline & $\begin{array}{c}\text { Source-Related } \\
\text { Impacts }\end{array}$ & $\begin{array}{c}\text { Make-Related } \\
\text { Impacts }\end{array}$ & $\begin{array}{c}\text { Delivery Related } \\
\text { Impacts }\end{array}$ & $\begin{array}{c}\text { Future Resilience } \\
\text { Strategies }\end{array}$ \\
\hline Source-related impacts & - & - & - & 1.819 \\
Make-related impacts & 1.000 & - & 1.215 & 1.272 \\
Delivery-related impacts & - & - & 1.215 & 1.815 \\
\hline
\end{tabular}

The validity and reliability of the developed model have been evaluated measuring the internal consistency reliability (by means of the Composite Reliability-CR and Rho Alpha), the Convergent validity (by means of the Average Variance Extracted-AVE), and the Discriminant validity (by means of the Fornell Larcker criterion analysis and HeterotraitMonotrait ratio of correlations-HTMT) [57]. Table 3 shows the results of the assessment, while Table 4 presents the HTMT ratios for the developed constructs. 
Table 2. Statistical tests on measurement indicators (NB: LSPs = logistics service providers; RMs = raw materials).

\begin{tabular}{|c|c|c|c|c|}
\hline $\begin{array}{l}\text { Measurement } \\
\text { Indicator }\end{array}$ & $\begin{array}{l}\text { Outer Model } \\
\text { Loadings }\end{array}$ & $\begin{array}{l}\text { Indicator } \\
\text { Reliability }\end{array}$ & $\begin{array}{l}\text { Variance Inflation } \\
\text { Factor (VIF) }\end{array}$ & Cross-Loadings \\
\hline Late deliveries & 0.918 & 0.842 & 1.635 & $\checkmark$ \\
\hline Raw materials shortages & 0.883 & 0.779 & 1.635 & $\checkmark$ \\
\hline Low capacity saturation & 0.672 & 0.451 & 1.146 & $\checkmark$ \\
\hline Manpower shortages & 0.932 & 0.868 & 1.146 & $\checkmark$ \\
\hline Low warehouse productivity & 0.791 & 0.625 & 1.336 & $\checkmark$ \\
\hline Carriers shortages & 0.767 & 0.588 & 1.384 & $\checkmark$ \\
\hline Stock shortages & 0.818 & 0.669 & 1.412 & $\checkmark$ \\
\hline Multiple sourcing for LSPs & 0.700 & 0.490 & 1.722 & $\checkmark$ \\
\hline Multiple sourcing for RM & 0.748 & 0.559 & 1.774 & $\checkmark$ \\
\hline Additional manpower & 0.746 & 0.556 & 1.309 & $\checkmark$ \\
\hline Product range prioritisation & 0.611 & 0.473 & 1.455 & $\checkmark$ \\
\hline Network re-design & 0.714 & 0.509 & 1.504 & $\checkmark$ \\
\hline
\end{tabular}

Table 3. Statistical tests on latent constructs (or internal consistency reliability tests).

\begin{tabular}{ccccc}
\hline Construct & $\begin{array}{c}\text { Composite } \\
\text { Reliability }\end{array}$ & Rho Alpha & AVE & $\begin{array}{c}\text { Fornell-Larcker } \\
\text { Criterion }\end{array}$ \\
\hline Source-related impacts & 0.783 & 0.895 & 0.881 & $\checkmark$ \\
Make-related impacts & 0.705 & 0.791 & 0.660 & $\checkmark$ \\
Delivery-related impacts & 0.710 & 0.835 & 0.628 & $\checkmark$ \\
Future resilience strategies & 0.771 & 0.831 & 0.498 & $\checkmark$ \\
\hline
\end{tabular}

Table 4. Heterotrait-monotrait (HTMT) ratios for the constructs.

\begin{tabular}{cccc}
\hline & $\begin{array}{c}\text { Source-Related } \\
\text { Impacts }\end{array}$ & $\begin{array}{c}\text { Make-Related } \\
\text { Impacts }\end{array}$ & $\begin{array}{c}\text { Delivery Related } \\
\text { Impacts }\end{array}$ \\
\hline Source-related impacts & - & - & - \\
Make-related impacts & 0.620 & - & - \\
Delivery-related impacts & 0.836 & 0.552 & - \\
Future resilience strategies & 0.143 & 0.846 & 0.350 \\
\hline
\end{tabular}

Table 3 indicates good validity and reliability levels of the measurement model, i.e., CR > 0.70; Rho Alpha > 0.7 and AVE > 0.5. The Fornell-Larcker criterion analysis shows that the square roots of AVE are higher than any correlation between the constructs. In Table 4 the HTMT ratios span from a minimum value 0.143 to a maximum value equal to 0.846 . Even though close to the threshold in one case (Source Impacts $\rightarrow$ Delivery Impacts) no value is above the threshold of 0.85 for conceptually different constructs [65].

\subsection{PLS Path Model}

To evaluate the main effects of the model, we assessed the path significance through a PLS algorithm and a bootstrapping procedure. We obtained the path coefficient values for each relationship and their $p$-values. The PLS algorithm was run to obtain the path coefficients; then, the bootstrapping procedure with 5000 random replications allowed for testing whether the relations between constructs were statistically significant. We took 0.05 as the threshold for the $p$-value and 1.96 as the critical value of the T-statistic (see Table 5). 
Table 5. Path significance tests $\left({ }^{*} p\right.$-values above $5 \%$ and T-statistics below 1.96$)$.

\begin{tabular}{cccc}
\hline & Path Coefficient & T-Statistics & $p$-Value \\
\hline Source-related impacts $\rightarrow$ Make-related impacts & 0.421 & 5.627 & 0.000 \\
Source-related impacts $\rightarrow$ Delivery-related impacts & 0.577 & 5.187 & 0.000 \\
Source-related impacts $\rightarrow$ Future resilience strategies & -0.342 & $1.812^{*}$ & $0.065^{*}$ \\
Make-related impacts $\rightarrow$ Delivery-related impacts & 0.176 & $1.319^{*}$ & $0.188^{*}$ \\
Make-related impacts $\rightarrow$ Future resilience strategies & 0.658 & 6.489 & 0.000 \\
Delivery-related impacts $\rightarrow$ Future resilience strategies & 0.162 & $1.046^{*}$ & $0.296^{*}$ \\
\hline
\end{tabular}

Figure 2 exhibits the results, where the diameter of the arrows represents the impact. Source-related impacts have the strongest effects on delivery-related impacts, since the associated path coefficient is 0.577 . At the same time, source-related impacts have a good positive effect on make-related impacts, represented by a path coefficient of 0.421 . By contrast, the relationship between make-related and delivery-related impacts seems to be weaker than the others, with a related coefficient equal to 0.176 . Concerning the relationships between SC impacts and future resilience strategies, the relevance of the makerelated impacts is important to determine the future interest towards resilience actions (path coefficient equal to 0.658). The model also suggests a weak positive relationship between delivery-related impacts and future resilience strategies, with an associated path coefficient equal to 0.162 . Interestingly, a negative path coefficient links source-related impacts to future resilience strategies $(-0.342)$, which appears to be counterintuitive.

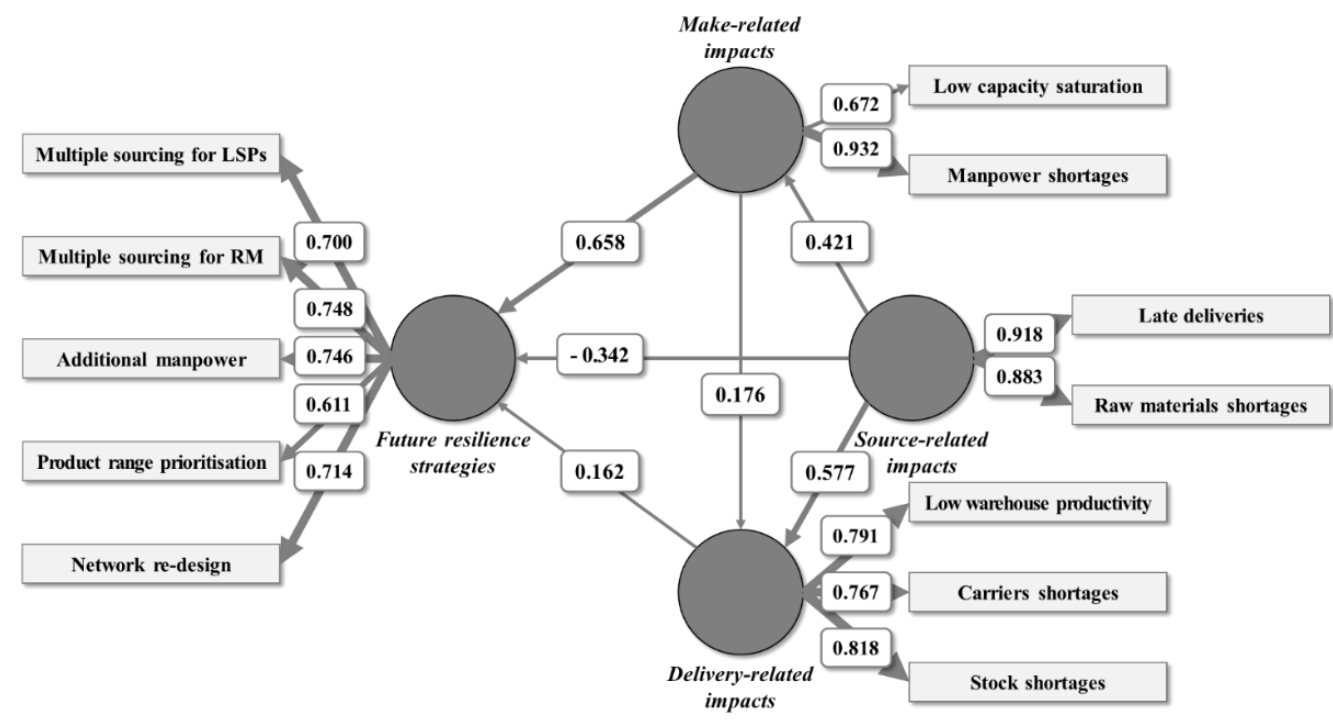

Figure 2. PLS-SEM algorithm results.

However, looking at the significance, this relationship cannot be considered as statistically significant, so it should be discarded along with two other relationships (make-related impacts $\rightarrow$ delivery-related impacts and delivery-related impacts $\rightarrow$ future resilience strategies-whose $p$-values and T-statistics values are outside the range of acceptability). Consequently, only the three following relationships were tested as significant from a relevance and statistical viewpoint: source-related impacts $\rightarrow$ make-related impacts, source-related impacts $\rightarrow$ delivery-related impacts, and make-related impacts $\rightarrow$ future resilience strategies.

As concerns the structural model, it was assessed in terms of quality through the evaluation of collinearity problems and overall fit and the model's explanatory power. The VIFs obtained from the analysis range from 1.000 to 1.815 , and consequently do not suggest any collinearity issue, as they are below the threshold value of 5 (Table 1). The strength of the relationship between pairs of variables was tested through Cohen's f2. Both the effect 
of make-related impacts on delivery-related impacts and of delivery-related impacts on future resilience strategies proved to be weak, with Cohen's f2 equal to 0.046 and 0.024, respectively. On the other hand, two medium-level effects have been shown by this test, particularly that of source-related impacts on future resilience strategies $(0.108$, thus in between weak and medium) and that of source-related impacts on make-related impacts (0.215, thus in between medium and strong). Finally, two substantial effects emerged from the analysis, i.e., that of source-related impacts on delivery-related impacts (0.497) and that of make-related impacts on future resilience strategies (0.570).

The explanatory power of the model was assessed through the measurement of the explained variance of an endogenous variable $\left(R^{2}\right)$. The make-related impacts construct is the most critical since the only variable that influences it in the model is the source-related impacts one. Thus, a value of explained variance of 0.177 stands for a weak representation of the construct's variability in the model, according to the literature suggestions. On the other hand, both delivery-related impacts and future resilience strategies' variabilities are moderately well-explained, since their $\mathrm{R}^{2}$ is 0.449 and 0.403 , respectively. In particular, it is important to notice that an explained variance of 0.403 for future resilience strategies comes from a good level of variability represented in the model by the 3 constructs in 'input', i.e., source-, make-, and delivery-related impacts. As for [62,65], the model fit in terms of estimation error and misspecification of the model was assessed through the standardised root mean square residuals (SRMR) indicator and the root mean square residual covariance (RMStheta) indicator. The value of SRMR equal to 0.082 is almost equal to the critical value of 0.08 , and the value of RMStheta equal to 0.176 is slightly over the threshold of 0.12 . The values of these indicators show that significant misspecification of the structural model is not present.

The predictive relevance of the model was measured through the value of StoneGeisser's Q2 for each endogenous variable. The Blindfolding procedure with omission distance equal to 7 was run [65]. The values of Q2 were all positive and largely higher than 0 (make-related impacts: 0.101; delivery-related impacts: 0.257 ; future resilience strategies: 0.160), which supported good predictive relevance of the model.

\section{Discussion}

These findings exhibit that the main element affecting perceptions about future resilience strategies is represented by the impacts experienced on the make-related side of the SC process. After having ascertained the quality of the measurement and structural models, and having retained only those relationships significant from a statistical viewpoint, it emerged that source-related impacts have a significant effect on make- and delivery-related impacts, and that make-related impacts have a considerable effect on future resilience strategies. This was confirmed by the $\mathrm{f} 2$ effects analysis, which showed a medium-strong effect of source-related impacts on make-related impacts in addition to a strong effect of source-related impacts on delivery-related impacts and of make-related impacts on future resilience strategies.

However, it also emerged that make-related impacts deeply affect the perceptions of grocery manufacturers, as they are the most important element in shaping the attitude towards various resilience strategies for the future. Among these, introducing additional manpower and activating multiple sourcing for raw materials are the resilience strategies foreseen as a priority for the future, followed, respectively, by logistics network redesign, the adoption of multiple sourcing for logistics services, and product range prioritisation. This evidence is in line with what one could expect from manufacturers, who normally consider the continuity of their production operations and the capability of delivering their products downstream in the SC as the main critical factors during emergencies [52]. Moreover, the analysis of the results also suggests that there is a considerable interrelationship among the impacts perceived by the manufacturers. Specifically, by combining sourceand make-related impacts it is possible to obtain an explanation of the impacts on the delivery side. In general, source-related impacts appear as relevant antecedents of make- 
and delivery-related impacts, and their indicators have high loadings values. This shows that there have been serious concerns regarding the continuity of supplies due to both late deliveries and raw materials shortages. However, the negative path coefficient that links source-related impacts to future resilience strategies could highlight that manufacturers are primarily interested in improving resilience regarding what they consider as being within their managerial scope. As inbound flows are usually managed by suppliers, a possible interpretation of the results is that manufacturers attribute source-related impacts to suppliers' failures; this does not raise their interest towards resilience initiatives. However, this is not coherent with a supply chain perspective as the manufacturers may look at single firms rather than considering the entire supply chain, neglecting how the effects of disruptions in a certain tier of the supply chain (e.g., suppliers) may propagate throughout the entire supply chain [9].

Looking at the loadings of the indicators of the other constructs related to the impacts, the highest values emerge for those items related to shortages (i.e., manpower shortages for the make-related impacts construct and stock shortages for the delivery-related impacts construct). This confirms the concerns of manufacturers related to the unavailability of supplies, stocks, and manpower. Indeed, during the pandemic absenteeism increased as health-screening protocols were enforced and employees with symptoms remained at home. Local containment policies also contributed to absenteeism, labour shortages, and interruptions. Interestingly, it also appears that make-related impacts are not strong predictors of delivery-related impacts, which are rather predicted more by source-related impacts. In this sense, source-related impacts are the strongest element determining in the first place the disruptions in the make- and delivery-related processes, potentially activating a trickle-down effect.

Nevertheless, it emerges that source-related impacts do not have a direct effect on the perception of SC managers in shaping their resilience strategies for the future. This could be due to the fact that source-related impacts are perceived as antecedents of the makeand delivery-related impacts. The perspective of the grocery manufacturers indicates that make-related impacts are the main predictors and antecedents of their future resilience strategies, and that delivery-related impacts follow from the source- and make-related impacts combined. In other words, manufacturers seem to perceive the impacts on the make-related process as the real drivers behind their choices on shaping future resilience strategies. This is also confirmed by the indicator loadings of the future resilience strategies construct. In fact, manufacturers are more interested in strategies ensuring the continuity of their manufacturing operations, but also positively evaluate other actions related to the downstream processes (e.g., product range prioritisation or the multiple sourcing of logistics services). This study shows that manufacturers are interested in product range prioritisation to guarantee supply, e.g., by suspending the production of long-tail products. This could help ensure greater total supplies of products and simplify SCs by focusing on fewer products. Additionally, creating a portfolio with multiple logistics service providers seems to be beneficial, as truck driver shortages led to a significant backlog in logistics with a short-term peak in transport demand (followed by a surplus capacity in transport) [6].

\section{Implications for Future Resilience Strategies}

One of the most popular strategies to arm against disruptions is to introduce inventory buffers and backup sources across the supply chain [34,69]. Stock is indeed a great buffer, but only when demand increases; it is not such a good solution if demand falls away overnight. In that case, the stock puts huge pressure on working capital. Redundant SC practices can buy time for a firm to recover from a disruption but there are associated costs, such as tying capital into inventory in addition to additional transaction costs from managing multiple suppliers that cannot be neglected [70]. Overall, redundancy is an expensive measure, and the trade-off between cost and resilience must be considered [71].

Trade-off theory is a dominant theoretical perspective in SC management [16,72], and the trade-off between the extra costs related to resilience strategies and the total SC costs 
is critical. Increasing robustness and agility requires the allocation of scarce resources, and companies must carefully examine what level of robustness and agility actually fits their competitive strategy [13]. At a glance, it could seem obvious that firms are now compelled to tackle SC risks just as vigorously as they tackle other business risks. However, before engaging in expensive actions firms need to develop appropriate studies about the probability of occurrence of SC disruptions and the potential effect of these disruptions on their performance [73].

Moreover, companies should acknowledge that many resilience challenges have arisen from an obsession with costs as well as a short-term cost focus [6]. Conversely, balanced resilience logic has been proposed to pursue a state of balance between investments and risk, thus encompassing a long-term perspective that could be beneficial $[9,74]$. The protection motivation theory (PMT) could thus be proposed as the theoretical lens through which to deepen and clarify future interest towards resilience [75]. Drawing from expectancy-value theory and cognitive processing theory, the PMT is one of the most powerful explanatory theories for predicting future intentions to engage in protective actions [76]. In more detail, it is based on the individual appraisal of possible threats and the personal capability to cope with those threats [75]. According to this view, it is essential to take into account the elements to be appraised in terms of threats and in terms of actions to cope with risk, because they constitute the foundations and backbone of any resilience initiative. This could be done in terms of threat appraisal, i.e., the perceived vulnerability, and of coping appraisal, i.e., the group of strategies needed. Companies could thus evaluate resilience strategies differently according to the expected benefits to identify a response that could be both efficient and effective.

\section{Conclusions}

The COVID-19 pandemic, including both the crisis and the recovery period, has provided rich opportunities to observe and study risk-related strategic and operational SC transformations [25]. Overall, concerns have emerged about vulnerability due to SC disruptions, in particular because of the shortages of critical goods. Consequently, the pandemic highlighted the need to rapidly redeploy resources to meet essential demands, also implying the movement of inventories closer to end customers to reduce the time to market. This study provides an answer to the presented research question examining which impacts might have a major role in affecting SC managers' perceptions and then in shaping the interest towards future resilience strategies. A survey instrument was developed, limiting the investigation to a specific empirical domain, considering Italian manufacturers active in the grocery industry.

The results show that source-related impacts deeply affect make- and delivery-related impacts, and that make-related impacts are the main element influencing the perception about future resilience strategies. In fact, such impacts contribute heavily to shaping the future approaches of manufacturers, who appear to be primarily interested in strategies ensuring the continuity of their manufacturing operations (e.g., introducing additional manpower and activating multiple sourcing for raw materials).

\subsection{Theoretical Implications}

From an academic viewpoint, this study first provides an empirical investigation of the relationships in place between SC negative impacts and also leverages the SCOR model, which is an original perspective through which to approach SCRM. Source, make, and deliver processes are affected by different risks, and this study offers a mid-range contribution by illustrating the SC impacts experienced in the Italian grocery industry.

Second, previous scholars investigated how resilience strategies positively affect performance outcomes and help mitigate risks and related impacts [11]. This study investigates how risk impacts lead to shaping resilience strategies in organisations' future plans, also highlighting that perception plays a key role in determining which policies and actions should be undertaken when risk management is concerned [20]. Third, the study proposes 
the PMT as a promising theoretical lens through which to further address this kind of problem [75]. It can help investigate how companies can draw up responses that should be both efficient and effective by predicting future intentions to engage in protective actions [76]. Scholars have mainly used the PMT to explain how individuals cope with personal threats, but our findings suggest that it could be applied to a supply chain context as well.

In the wake of the many risks that characterise current SCs, this study can enlighten the mechanisms that managers leverage to cope with emerging threats.

\subsection{Managerial Implications}

From a managerial viewpoint, this study collects first-hand evidence concerning the influence that different SC impacts could have on each other, as well as how they could foster the adoption of future resilience strategies. This could inform practices in terms of the consequences of unexpected disruptions on SCs, highlighting the interdependence among different SC processes. Additionally, managers could identify prompt insights with which to inform their current decision making and improve their SCs' resilience. Indeed, the human factor is increasingly relevant in risk management, and perceptions are deemed as important as on-field data. Moreover, grocery SCs have been planning for changes in consumers' expectations and online behaviour, but they have generally assumed that these changes would have occurred over a fairly long period of time. COVID-19 has accelerated these changes almost overnight, leaving most SCs unprepared to respond. As companies look to the future they need to shed light onto the darkness, and this study could hopefully support managers in both the short and the medium term. A set of pragmatic strategies is proposed, presenting their suitability to address impacts that originate in specific SC tiers but then expand across the entire SC. Furthermore, this study shows a typical orientation of manufacturing companies as far as resilience is concerned, i.e., make-related impacts seem to be the drivers shaping their future resilience strategies, showing that manufacturers tend to embrace what they see within their managerial scope. This shows a lack of supply chain orientation with a focus on the boundaries of single organisations rather than on the whole supply chain. The opportunity to overcome this orientation is another managerial implication of our research.

\subsection{Limitations and Future Research Directions}

Along with its contributions, the limitations of this study should also be acknowledged as they open up promising future research avenues. Being exploratory in nature, this study did not tackle explicit propositions or hypotheses. Conversely, it investigated the relationships in place between different constructs, to study if and to what extent they might exist and be significant in addition to how they can be shaped. The small sample size, adopted methodology, and exploratory nature of this study pose some limitations to the generalisability of the obtained results. Hence, this study's findings could thus be tested by new research, e.g., by taking into account the PMT to investigate threat and coping appraisal. Additionally, the considered empirical domain could be broadened to increase the sample size and improve the findings' generalisability. This study is limited to Italian grocery manufacturers that experienced negative impacts during the first wave of the COVID-19 pandemic, but other actors, industries, and countries could be explored to cross-fertilise the emerging insights.

Author Contributions: Conceptualisation, L.B.P. and A.C.; methodology and software, A.C.; validation, L.B.P.; formal analysis, L.B.P. and A.C.; data curation, L.B.P. and A.C.; writing-original draft preparation, L.B.P. and A.C.; writing-review and editing, A.C. and L.B.P.; visualisation, M.M. and F.D. All authors have read and agreed to the published version of the manuscript.

Funding: This research received no external funding.

Institutional Review Board Statement: This study was conducted according to the guidelines of the Declaration of Helsinki and approved by the Research Project Review Group of LIUC University (Date: April 2020). 
Informed Consent Statement: Informed consent was obtained from all subjects involved in the study.

Data Availability Statement: The data presented in this study are available on request from the corresponding author. The data are not publicly available due to confidentiality reasons.

Conflicts of Interest: The authors declare no conflict of interest.

\section{Appendix A. Survey Questionnaire}

Appendix A.1. Company and Respondent Information

- Annual company turnover in 2019 (in Italy):

$$
\begin{aligned}
& \text { <€10 M. } \\
& € 10-49 \mathrm{M} \text {. } \\
& € 50-100 \mathrm{M} \text {. } \\
& €>100 \mathrm{M} \text {. }
\end{aligned}
$$

- Your Job Title/Role:

- Number of years of working experience in the Fast-Moving Consumer Goods sector:

- Number of years of working experience in your role at your current company:

\section{Appendix A.2. Impacts of COVID-19 on Supply Chain Processes}

Please evaluate the severity of the impacts (from $1=$ null or very minor to $5=$ major or disastrous) suffered by your company in relation to (Adapted from [6,22,35]):

- $\quad$ Late deliveries from suppliers.

- Shortage of raw materials.

- Reduced operational capacity at plants.

- Manpower shortages at plants.

- Reduced operational capacity at warehouses due to restrictions in place.

- Drivers' shortages.

- Finished products shortages.

\section{Appendix A.3. Level of Interest towards Future Supply Chain Resilience Strategies}

Based on your experience of the impacts of disruptions related to COVID-19 on your company's supply chain (if any), please evaluate how important the following strategies will be in the future for improving the level of resilience of your company's supply chain (from $1=$ not at all important to $5=$ very important) (Adapted from $[6,9,22]$ ):

- Multiple sourcing for raw materials.

- Multiple sourcing for logistics services.

- Additional operational capacity in terms of additional manpower.

- Flexible order allocation policies in terms of product range prioritisation.

- Network re-design in terms of inventory positioning closer to customers.

\section{References}

1. Noy, I.; Yonson, R. Economic Vulnerability and Resilience to Natural Hazards: A Survey of Concepts and Measurements. Sustainability 2018, 10, 2850. [CrossRef]

2. Wieland, A. Dancing the Supply Chain: Toward Transformative Supply Chain Management. J. Supply Chain Manag. 2021, 57, 58-73. [CrossRef]

3. Ali, I.; Nagalingam, S.; Gurd, B. A resilience model for cold chain logistics of perishable products. Int. J. Logist. Manag. 2018, 29, 922-941. [CrossRef]

4. Li, R.; Dong, Q.; Jin, C.; Kang, R. A New Resilience Measure for Supply Chain Networks. Sustainability 2017, 9, 144. [CrossRef]

5. Christopher, M.; Holweg, M. Supply chain 2.0 revisited: A framework for managing volatility-induced risk in the supply chain. Int. J. Phys. Distrib. Logist. Manag. 2017, 47, 2-17. [CrossRef]

6. van Hoek, R. Research opportunities for a more resilient post-COVID-19 supply chain-Closing the gap between research findings and industry practice. Int. J. Prod. Oper. Manag. 2020, 40, 341-355. [CrossRef]

7. Rajak, S.; Mathiyazhagan, K.; Agarwal, V.; Sivakumar, K.; Kumar, V.; Appolloni, A. Issues and analysis of critical success factors for the sustainable initiatives in the supply chain during COVID-19 pandemic outbreak in India: A case study. Res. Transp. Econ. 2021, 101114. [CrossRef] 
8. Hobbs, J.E. Food supply chains during the COVID-19 pandemic. Can. J. Agric. Econ. 2020, 68, 171-176. [CrossRef]

9. Chowdhury, P.; Paul, S.K.; Kaisar, S.; Moktadir, M.A. COVID-19 pandemic related supply chain studies: A systematic review. Transp. Res. Part E Logist. Transp. Rev. 2021, 148, 102271. [CrossRef]

10. Trabucco, M.; De Giovanni, P. Achieving Resilience and Business Sustainability during COVID-19: The Role of Lean Supply Chain Practices and Digitalization. Sustainability 2021, 13, 12369. [CrossRef]

11. Shekarian, M.; Mellat Parast, M. An Integrative approach to supply chain disruption risk and resilience management: A literature review. Int. J. Logist. Res. Appl. 2020, 24, 427-455. [CrossRef]

12. Ponomarov, S.Y.; Holcomb, M.C. Understanding the concept of supply chain resilience. Int. J. Logist. Manag. 2009, 20, 124-143. [CrossRef]

13. Wieland, A.; Wallenburg, C.M. Dealing with supply chain risks: Linking risk management practices and strategies to performance. Int. J. Phys. Distrib. Logist. Manag. 2012, 42, 887-905. [CrossRef]

14. Clarvis, M.H.; Bohensky, E.; Yarime, M. Can Resilience Thinking Inform Resilience Investments? Learning from Resilience Principles for Disaster Risk Reduction. Sustainability 2015, 7, 9048-9066. [CrossRef]

15. Hohenstein, N.-O.; Feisel, E.; Hartmann, E.; Giunipero, L. Research on the phenomenon of supply chain resilience: A systematic review and paths for further investigation. Int. J. Phys. Distrib. Logist. Manag. 2015, 45, 90-117. [CrossRef]

16. Esmizadeh, Y.; Mellat Parast, M. Logistics and supply chain network designs: Incorporating competitive priorities and disruption risk management perspectives. Int. J. Logist. Res. Appl. 2020, 24, 174-197. [CrossRef]

17. Zavala-Alcivar, A. A Conceptual Framework to Manage Resilience and Increase Sustainability in the Supply Chain. Sustainability 2020, 12, 6300. [CrossRef]

18. Colicchia, C.; Strozzi, F. Supply chain risk management: A new methodology for a systematic literature review. Supply Chain Manag. 2012, 17, 403-418. [CrossRef]

19. Norrman, A.; Wieland, A. The development of supply chain risk management over time: Revisiting Ericsson management. Int. J. Phys. Distrib. Logist. Manag. 2020, 50, 641-666. [CrossRef]

20. Creazza, A.; Colicchia, C.; Italy, I.; Dallari, F. Who cares? Supply chain managers' perceptions regarding cyber supply chain risk management in the digital transformation era Salvatore Spiezia. Supply Chain Manag. Int. J. 2021, 27, 30-53. [CrossRef]

21. Stank, T.P.; Pellathy, D.A.; In, J.; Mollenkopf, D.A.; Bell, J.E. New Frontiers in Logistics Research: Theorizing at the Middle Range. J. Bus. Logist. 2017, 38, 6-17. [CrossRef]

22. Singh, S.; Kumar, R.; Panchal, R.; Tiwari, M.K. Impact of COVID-19 on logistics systems and disruptions in food supply chain. Int J. Prod. Res. 2020, 59, 1993-2008. [CrossRef]

23. Napoleone, A.; Prataviera, L.B. Reconfigurable manufacturing: Lesson learnt from the COVID-19 outbreak. In Proceedings of the IFIP International Conference on Advances in Production Management Systems, Novi Sad, Serbia, 30 August-3 September 2020; Springer: Cham, Germany; pp. 457-465. [CrossRef]

24. Vagni, M.; Maiorano, T.; Giostra, V.; Pajardi, D. Hardiness, Stress and Secondary Trauma in Italian Healthcare and Emergency Workers during the COVID-19 Pandemic. Sustainability 2020, 12, 5592. [CrossRef]

25. Sarkis, J. Supply chain sustainability: Learning from the COVID-19 pandemic. Int. J. Oper. Prod. Manag. 2020, 41, 63-73. [CrossRef]

26. Norrman, A.; Jansson, U. Ericsson's proactive supply chain risk management approach after a serious sub-supplier accident. Int J. Phys. Distrib. Logist. Manag. 2004, 34, 434-456. [CrossRef]

27. Knemeyer, A.M.; Zinn, W.; Eroglu, C. Proactive planning for catastrophic events in supply chains. J. Oper. Manag. 2009, 27, 141-153. [CrossRef]

28. Christopher, M.; Peck, H. Building the Resilient Supply Chain. Int. J. Logist. Manag. 2004, 15, 1-14. [CrossRef]

29. Jüttner, U. Supply chain risk management: Understanding the business requirements from a practitioner perspective. Int. J. Logist. Manag. 2005, 16, 120-141. [CrossRef]

30. Rao, S.; Goldsby, T.J. Supply chain risks: A review and typology. Int. J. Logist. Manag. 2009, 20, 97-123. [CrossRef]

31. Zsidisin, G.A.; Ellram, L.M.; Carter, J.R.; Cavinato, J.L. An analysis of supply risk assessment techniques. Int. J. Phys. Distrib. Logist. Manag. 2004, 34, 397-413. [CrossRef]

32. Colicchia, C.; Creazza, A.; Menachof, D.A. Managing cyber and information risks in supply chains: Insights from an exploratory analysis. Supply Chain Manag. 2019, 24, 215-240. [CrossRef]

33. Rangel, D.A.; de Oliveira, T.K.; Leite, M.S.A. Supply chain risk classification: Discussion and proposal. Int. J. Prod. Res. 2015, 53, 6868-6887. [CrossRef]

34. Kleindorfer, P.R.; Saad, G.H. Managing disruption risks in supply chain. Prod. Oper. Manag. 2005, 14, 53-68. [CrossRef]

35. Wagner, S.M.; Bode, C. An empirical investigation into supply chain vulnerability. J. Purch. Supply Manag. 2006, 12, $301-312$. [CrossRef]

36. Chen, J.; Sohal, A.S.; Prajogo, D.I. Supply chain operational risk mitigation: A collaborative approach. Int. J. Prod. Res. 2013, 51, 2186-2199. [CrossRef]

37. Tang, C.S. Robust strategies for mitigating supply chain disruptions. Int. J. Logist. Res. Appl. 2006, 9, 33-45. [CrossRef]

38. Huan, S.H.; Sheoran, S.K.; Wan, G. A review and analysis of supply chain operations reference (SCOR) model. Supply Chain Manag. 2004, 9, 23-29. [CrossRef] 
39. Rotaru, K.; Wilkin, C.; Ceglowski, A. Analysis of SCOR's approach to supply chain risk management. Int. J. Oper. Prod. Manag. 2014, 34, 1246-1268. [CrossRef]

40. Sreedevi, R.; Saranga, H. Uncertainty and supply chain risk: The moderating role of supply chain flexibility in risk mitigation. Int. J. Prod. Econ. 2017, 193, 332-342. [CrossRef]

41. Zhou, H.; Benton, W.C.; Schilling, D.A.; Milligan, G.W. Supply chain integration and the SCOR model. J. Bus. Logist. 2011, 32, 332-344. [CrossRef]

42. Craighead, C.W.; Blackhurst, J.; Rungtusanatham, M.J.; Handfield, R.B. The severity of supply chain disruptions: Design characteristics and mitigation capabilities. Decis. Sci. 2007, 38, 131-156. [CrossRef]

43. Lepore, D.; Micozzi, A. Industry 4.0 Accelerating Sustainable Manufacturing in the COVID-19 Era: Assessing the Readiness and Responsiveness of Italian Regions. Sustainability 2021, 13, 2670. [CrossRef]

44. Hosseini, S.; Ivanov, D.; Dolgui, A. Review of quantitative methods for supply chain resilience analysis. Transp. Res. Part E Logist. Transp. Rev. 2019, 125, 285-307. [CrossRef]

45. Durach, C.F.; Wieland, A.; Machuca, J.A.D. Antecedents and dimensions of supply chain robustness: A systematic literature review. Int. J. Phys. Distrib. Logist. Manag. 2015, 45, 118-137. [CrossRef]

46. Stone, J.; Rahimifard, S. Resilience in agri-food supply chains: A critical analysis of the literature and synthesis of a novel framework. Supply Chain Manag. 2018, 23, 207-238. [CrossRef]

47. Wieland, A.; Wallenburg, C.M. The influence of relational competencies on supply chain resilience: A relational view. Int. J. Phys. Distrib. Logist. Manag. 2013, 43, 300-320. [CrossRef]

48. Sheffi, Y.; Rice, J.B. A supply chain view of the resilient enterprise. MIT Sloan Manag. Rev. 2005, 47, 41-48.

49. Mathiyazhagan, K.; Agarwal, V.; Appolloni, A.; Saikouk, T.; Gnanavelbabu, A. Integrating lean and agile practices for achieving global sustainability goals in Indian manufacturing industries. Technol. Forecast. Soc. Chang. 2021, 171, 120982. [CrossRef]

50. Forza, C. Survey research in operations management: A process-based perspective. Int. J. Oper. Prod. Manag. 2002, 22, 152-194. [CrossRef]

51. Caniato, F.; Doran, D.; Sousa, R.; Boer, H. Designing and developing OM research-From concept to publication. Int. J. Oper. Prod. Manag. 2018, 38, 1836-1856. [CrossRef]

52. Colicchia, C.; Creazza, A.; Dallari, F. Lean and green supply chain management through intermodal transport: Insights from the fast moving consumer goods industry. Prod. Plan. Control 2017, 28, 321-334. [CrossRef]

53. Prataviera, L.B.; Creazza, A.; Dallari, F.; Melacini, M. How can logistics service providers foster supply chain collaboration in logistics triads? Insights from the Italian grocery industry. Supply Chain Manag. Int. J. 2021. [CrossRef]

54. Punch, K.F. Introduction to Social Research: Quantitative and Qualitative Approaches; SAGE Publications: London, UK, 2005; ISBN 0761944176.

55. Jabbour, C.J.C.; de Sousa Jabbour, A.B.L.; Govindan, K.; de Freitas, T.P.; Soubihia, D.F.; Kannan, D.; Latan, H. Barriers to the adoption of green operational practices at Brazilian companies: Effects on green and operational performance. Int. J. Prod. Res. 2016, 54, 3042-3058. [CrossRef]

56. Wong, K.K.-K. Partial least squares structural equation modeling (PLS-SEM) techniques using SmartPLS. Mark. Bull. 2013, 24, $1-32$.

57. Cohen, J. A Power Primer. Psychol. Bull. 1992, 112, 155-159. [CrossRef]

58. Hair, J.F.; Risher, J.J.; Sarstedt, M.; Ringle, C.M. When to use and how to report the results of PLS-SEM. Eur. Bus. Rev. 2019, 31, 2-24. [CrossRef]

59. Joshi, A.; Kale, S.; Chandel, S.; Pal, D.K. Likert Scale: Explored and Explained. Br. J. Appl. Sci. Technol. 2015, 7, 396-403. [CrossRef]

60. Couper, M.P. Web Surveys: A Review of Issues and Approaches. Public Opin. Q. 2000, 64, 464-494. [CrossRef]

61. Zheng, T.; Ardolino, M.; Bacchetti, A.; Perona, M.; Zanardini, M. The impacts of Industry 4.0: A descriptive survey in the Italian manufacturing sector. J. Manuf. Technol. Manag. 2019, 31, 1085-1115. [CrossRef]

62. Hair, J.F.; Hult, G.T.M.; Ringle, C.M.; Sarstedt, M. A Primer on Partial Least Squares Structural Equation Modeling (PLS-SEM); Sage Publications: London, UK, 2014.

63. Yamin, M.A. Investigating the Drivers of Supply Chain Resilience in the Wake of the COVID-19 Pandemic: Empirical Evidence from an Emerging Economy. Sustainability 2021, 13, 11939. [CrossRef]

64. Leguina, A. A primer on partial least squares structural equation modeling (PLS-SEM). Int. J. Res. Method Educ. 2015, 38, 220-221. [CrossRef]

65. Sodhi, M.S.; Son, B.G.; Tang, C.S. Researchers' perspectives on supply chain risk management. Prod. Oper. Manag. 2012, 21, 1-13. [CrossRef]

66. Podsakoff, P.M.; MacKenzie, S.B.; Lee, J.Y.; Podsakoff, N.P. Common Method Biases in Behavioral Research: A Critical Review of the Literature and Recommended Remedies. J. Appl. Psychol. 2003, 88, 879-903. [CrossRef] [PubMed]

67. Kock, N.; Lynn, G.S. Lateral Collinearity and Misleading Results in Variance-Based SEM: An Illustration and Recommendations. J. Assoc. Inf. Syst. 2012, 13, 546-580. [CrossRef]

68. Richardson, H.A.; Simmering, M.J.; Sturman, M.C. A Tale of Three Perspectives. Organ. Res. Methods 2009, 12, 762-800. [CrossRef]

69. Tang, C.S. Perspectives in supply chain risk management. Int. J. Prod. Econ. 2006, 103, 451-488. [CrossRef]

70. Zsidisin, G.A.; Wagner, S.M. Do Perceptions Become Reality? the Moderating Role of Supply Chain Resiliency on Disruption Occurrence. J. Bus. Logist. 2010, 31, 1-20. [CrossRef] 
71. Chang, W.; Ellinger, A.E.; Blackhurst, J. A contextual approach to supply chain risk mitigation. Int. J. Logist. Manag. 2015, 26, 642-656. [CrossRef]

72. Skinner, W. Manufacturing-Missing Link in Corporate Strategy. Harv. Bus. Rev. 1969, 47, 136-145.

73. Wagner, S.M.; Bode, C. An Empirical Examination of Supply Chain Performance Along Several Dimensions of Risk. J. Bus. Logist. 2008, 29, 307-325. [CrossRef]

74. Gualandris, J.; Kalchschmidt, M. Supply risk management and competitive advantage: A misfit model. Int. J. Logist. Manag. 2015, 26, 459-478. [CrossRef]

75. Milne, S.; Sheeran, P.; Orbell, S. Prediction and intervention in health-related behavior: A meta-analytic review of protection motivation theory. J. Appl. Soc. Psychol. 2000, 30, 106-143. [CrossRef]

76. Anderson, C.L.; Agarwal, R. Practicing Safe Computing: A Multimethod Empirical Examination of Home Computer User Security Behavioral Intentions. MIS Q. 2010, 34, 613-643. [CrossRef] 